\title{
A proposed new metallogenic model of Mesozoic W-dominated polymentallic deposits in South \\ China
}

\author{
ZHENG ZHAO $^{1}$, WEN ZHAO ${ }^{2}$
}

${ }^{1}$ Chinese Academy of Geological Sciences, Beijing 100037, China_kevin8572@hotmail.com

${ }^{2}$ Department of Earth Sciences, The University of Hong Kong, Pokfulam Road, Hong Kong, China zhaowen@connect.hku.hk

The tungsten mineral resources in South China account for more than $80 \%$ of China and about $45 \%$ of the world, and there are thousands of world-class large tungsten deposits that are rich in types. In this paper, based on previous studies of tungsten deposits in South China, combined with recent exploration discoveries (Zhuxi, Dahutang and Pangushan NLSD-2) and new progress (Baxiannao and Taoxikeng), accorded to the genetic types, the tungsten deposits of South China are divided into 9 types. According to the evolution features of geological tectonic units and the spatial-temporal distribution of tungsten deposits in South China, tungsten deposits in South China can be divided into the Eastern Yangtze W Belt (EYB) with W deposits concentrate forming in 150 135 Ma, the Nanling W metallogenic Belt (NLB) with $\mathrm{W}$ deposits concentrate forming in 165 150 Ma, Southeast Coast W metallogenic Belt (SCB) with W-dominant deposits concentrate forming in $100 \sim 80 \mathrm{Ma}$. According to the spatial relationship between different types of tungsten bodies and ore-forming granites in South China, and based on the differences between ore controlling strata and ore controlling structures, the granitoid related tungsten metallogenic model is established. From the southeast coast to the inland, the deep part undergoes west-toward subduction, retreating and conversion of the paleo Pacific plate during Mesozoic, furthermore, deep faults in different areas enhances the local crust-mantle interaction, and tungsten deposits types and temporal-spatial distribution of Mesozoic in different zones have good correspondence to deep process. 